\title{
ANATOMIA DO LENHO DE DUAS ESPÉCIES DE ALOYSIA (VERBENACEAE) ${ }^{1}$
}

\author{
ANELISE MARTA SIEGLOCH ${ }^{2}$ JOSÉ NEWTON CARDOSO MARCHIORI ${ }^{3}$ \\ SIDINEI RODRIGUES DOS SANTOS ${ }^{4}$
}

\section{RESUMO}

São anatomicamente descritos os lenhos de Aloysia chamaedryfolia Cham. e Aloysia gratissima (Gillies \& Hook. ex Hook.) Tronc. Ambas as espécies apresentam: vasos de diâmetro pequeno, em múltiplos radiais; elementos vasculares de comprimento médio, providos de espessamentos espiralados e apêndices; placas de perfuração simples, em sua maioria; pontoações intervasculares de diâmetro médio, alternas e ornamentadas; pontoações raio-vasculares aparentemente simples; parênquima paratraqueal-escasso; raios heterogêneos; e fibras libriformes septadas. A largura de raios em número de células permite a separação de ambas as espécies.

Palavras-chave: Aloysia chamaedryfolia, Aloysia gratissima, Anatomia da Madeira, Verbenaceae.

\section{ABSTRACT}

[Wood anatomy of two species of Aloysia (Verbenaceae)].

The wood anatomy of Aloysia chamaedryfolia Cham. and Aloysia gratissima (Gillies \& Hook. ex Hook.) Tronc. are described. Both species present: small diameter vessels, in radial multiple pores; vascular elements of medium length, with spiral thickenings and appendices; simple perforation plates; medium size intervascular pits, with alternate-ornamented bordered pits; seemingly simple ray-vascular pits; scarce paratracheal parenchyma; heterogeneous rays; and libriform septate fibres. Both species can be segregated by width rays in number of cells.

Key words: Aloysia chamaedryfolia, Aloysia gratissima, Verbenaceae, Wood Anatomy.

\section{INTRODUÇÃO}

De distribuição pantropical, com cerca de 36 gêneros e 1000 espécies, a família Verbenaceae é representada por ervas, arbustos, menos frequentemente árvores e lianas, geralmente aromáticas e de ramos quadrangulares. Após a segregação das Lamiaceae, a família ficou restrita, basicamente, à antiga subfamília Verbenoideae (Souza \& Lorenzi, 2012).

Entre as Verbenaceae incluem-se espécies ornamentais, como Petrea volubilis, Duranta

\footnotetext{
I Recebido para publicação em 14/05/2013 e aceito para publicação em 10/07/2013.

2 Mestranda do Curso de Pós-Graduação em Engenharia Florestal. Bolsista CAPES. Universidade Federal de Santa Maria. CEP 97105-900. Santa Maria, RS, Brasil. anesiegloch@yahoo.com.br

3 Engenheiro Florestal, Dr. Bolsista de Produtividade em Pesquisa (CNPq - Brasil). Professor Titular do Departamento de Ciências Florestais, Universidade Federal de Santa Maria. Santa Maria, RS, Brasil.

4 Biólogo, Dr. Núcleo de Estudos Botânicos Balduino Rambo, UFSM.
}

repens e Lantana camara. Nos campos rupestres brasileiros são comuns espécies de Lippia e Stachytarpheta; nas matas ciliares e florestas estacionais do sul do Brasil salienta-se Citharexylum myrianthum (Souza \& Lorenzi, 2012).

O gênero Aloysia Paláu, compreende cerca de trinta espécies de arbustos aromáticos, bem conhecidos por sua riqueza em óleos essenciais (Hernandes et al., 2003). No presente estudo, são investigados os lenhos de duas espécies desse gênero.

Nativa no sul do Brasil, noroeste da Argentina e Uruguai, Aloysia chamaedrifolia Cham. é arbusto de $1,5 \mathrm{~m}$ de altura, com ramos quadrangulares, pubescentes e folhas simples, opostas, discolores $(0,5-2 \mathrm{~cm}$ x 1-2 cm), de bordos serrados. Trata-se de espécie ornamental, pela vistosa e perfumada floração de fins da primavera e verão (Brussa \& Grella, 2007).

Aloysia gratissima (Gillies \& Hook. ex Hook.) Tronc. é valorizada por seu óleo essen- 
cial, contendo ácidos graxos, fenóis, hidrocarbonetos e outras substâncias. Polimorfa, a espécie distribui-se em duas áreas disjuntas: a primeira, nos Estados Unidos e México; e a segunda, na metade norte da Argentina, Bolívia, sul do Brasil, Paraguai e Uruguai. Arbusto caducifólio, de 2-3 m de altura, apresenta folhas simples, opostas, discolores $(0,3-0,8 \mathrm{~cm} \mathrm{x}$ 0,5-2 cm) e de bordos serrados; as flores, muito perfumadas, aparecem na primavera e verão (Brussa \& Grella, 2007).

Com relação à anatomia do lenho, Metcalfe $\&$ Chalk (1972) relacionam os seguintes caracteres para as Verbenaceae: vasos de diâmetro médio, em padrão radial, oblíquo ou tangencial; porosidade comumente em anel; elementos vasculares de comprimento médio a muito curto; placas de perfuração simples, embora escalariformes e/ou reticuladas em alguns gêneros; pontoações intervasculares diminutas a moderadamente grandes; pontoações raiovasculares semelhantes, em sua maioria; parênquima paratraqueal, estreito-vasicêntrico, por vezes abundante e confluente; raios heterogêneos a homogêneos, com 3-4 células de largura, por vezes muito largos; e fibras com pontoações simples, geralmente septadas e de comprimento médio a moderadamente curto.

A diversidade de tipos de placas de perfuração é caráter marcante na família, sendo notadas placas simples, raro escalariformes, reticuladas ou combinação de placas simples e escalariformes (Record \& Hess, 1949; Metcalfe \& Chalk, 1972, Meylan \& Butterfield, 1975). Para Citharexylum myrianthum Cham., Gomes et al. (1989) descrevem placas simples, juntamente com placas radiadas e foraminadoradiadas. Para Citharexylum fruticosum, Gottwald \& Parameswaram (1964) referem placas tipicamente reticuladas e foraminadoreticuladas. Placas simples (maioria) e multiperfuradas, por sua vez, dos tipos escalariforme, irregularmente reticulada, foraminadoradiada e radiada, constam para Cytharexxylum solanaceum Cham. (Gomes et al, 2008). Sobre, este ponto, todavia, vale ressaltar que o caráter, embora possível de detecção em microscopia fotônica, ganha nitidez sob microscopia eletrônica de varredura.

O presente estudo visa a descrição e análise da estrutura do lenho de Aloysia chamaedrifolia e Aloysia gratissima, bem como reconhecer caracteres de valor taxonômico para o gênero em questão.

\section{MATERIAL E MÉTODOS}

No presente estudo foram analisadas duas amostras de madeira, conservadas na Xiloteca do Herbário do Departamento de Ciências Florestais (HDCF) da Universidade Federal de Santa Maria com os seguintes registros: Aloysia chamaedryfolia Cham., Pilão d'água (SantiagoRS), HDCF 755; Aloysia gratissima (Gillies \& Hook. ex Hook.) Tronc., rio Ibirocai (AlegreteRS), HDCF 574.

Para a confecção de lâminas histológicas foram extraídos três corpos de prova da parte mais externa do lenho $(1 \times 2 \times 3 \mathrm{~cm})$ para cada uma das espécies, próxima ao câmbio, orientados para a obtenção de cortes nos planos transversal, longitudinal radial e longitudinal tangencial; um quarto bloquinho foi também preparado, com vistas à maceração.

A confecção de lâminas permanentes seguiu a metodologia descrita em Burger \& Richter (1991). No preparo de lâminas de macerado seguiu-se o método de Jeffrey (Freund, 1970). As secções anatômicas foram tingidas com acridina-vermelha, crisoidina e azul-de-astra (Dujardin, 1964); o macerado, apenas com safranina $1 \%$. Na montagem das lâminas permanentes usou-se Entellan.

As descrições basearam-se nas recomendações da IAWA (Wheeler et al., 1989). No caso da percentagem dos tecidos foram realizadas 600 determinações ao acaso, com auxílio de contador de laboratório, conforme proposto por Marchiori (1980). A frequência de poros foi 
obtida a partir de um quadrado de área conhecida, superposto a fotomicrografias de seções transversais da madeira.

As medições foram realizadas em microscópio Carl Zeiss, no Laboratório de Anatomia da Madeira da Universidade Federal de Santa Maria. Nas características quantitativas, os números entre parênteses equivalem aos valores mínimos e máximos observados; o valor que acompanha a média é o desvio padrão. As fotomicrografias foram tomadas em microscópio Olympus CX40, equipado com câmera digital Olympus Camedia c3000, no Laboratório de Anatomia da Madeira da Universidade Federal do Paraná.

\section{DESCRIÇÃO ANATÔMICA}

\section{1 - Aloysia chamaedryfolia Cham.}

Anéis de crescimento: distintos, marcados por delgada camada de fibras radialmente estreitas, bem como pela redução no diâmetro de vasos no lenho tardio e pela concentração de vasos maiores no lenho inicial, aspectos que conferem aspecto anelar ao corte transversal (Figura 1A,B).

Vasos: extremamente numerosos $(223 \pm 40,6$ $(175-275)$ poros $\left./ \mathrm{mm}^{2}\right)$, ocupando $25,3 \pm 2,9 \%$ do volume da madeira. Porosidade semi-difusa, tendente a anelar. Poros solitários, em múltiplos radiais de 2-10, menos comumente racemiformes; de seção angular/poligonal (37 $\pm 7,1(22,5-47,5) \mu \mathrm{m})$ e paredes delgadas $(2,3$ $\pm 0,4(1,3-2,5) \mu \mathrm{m})$ (Figura 1A,B). Conteúdos, pouco frequentes. Elementos vasculares de comprimento médio $(364 \pm 62(230-460) \mu \mathrm{m})$, com placas de perfuração simples, menos comumente escalariformes, tendentes a reticuladas. Apêndices de 20-120 $\mu \mathrm{m}$, em uma ou em ambas as extremidades. Espessamentos espiralados, presentes. Pontoações intervasculares circulares $(8,4 \pm 0,8(7,2-9,3) \mu \mathrm{m})$, alternas, com abertura em fenda inclusa, ornamentada. Pontoações raio-vasculares aparentemente simples, alternas $(5,2 \pm 0,7(4,1$ $-6,2) \mu \mathrm{m})$.
Parênquima axial: representando 5,5 $\pm 1,8 \%$ do volume da madeira; em arranjo paratraquealescasso (Figura 1A,B). Séries parenquimáticas de $316 \pm 62,3(205-395) \mu \mathrm{m}$ de altura, compostas de $2-4$ células.

Raios: numerosos $(10 \pm 1,7(7-12)$ raios/ $\mathrm{mm})$, heterogêneos e com 1-3 células de largura, ocupando $15,8 \pm 2,2 \%$ do volume da madeira (Figura 1E,F). Os multisseriados, com células procumbentes no corpo central e 1-4 fileiras de células eretas e/ou quadradas, em margens mais curtas do que o corpo central; de $348 \pm$ $85,9(200-540) \mu \mathrm{m}$ e $6-21$ células de altura (Figura 1C,D). Os unisseriados, menos frequentes, de células quadradas e eretas, com $194 \pm$ 37,4 (120 - 260) $\mu \mathrm{m}$ e 3-9 células de altura (Figura 1C,D). Células radiais de paredes disjuntas e células perfuradas de raio, presentes. Raios agregados, células envolventes, cristais e conteúdos, ausentes. Raios axialmente fusionados, pouco frequentes.

Fibras: com pontoações simples, nas faces radiais e tangenciais da parede; curtas (706 \pm $75(570-850) \mu \mathrm{m})$, de $19 \pm 3,4(15-30) \mu \mathrm{m}$ de largura e paredes finas a espessas $(4 \pm 0,8(2,5$ - 6) $\mu \mathrm{m}$ ), ocupando $53,3 \pm 3,7 \%$ do volume da madeira (Figura 1A,B). Fibras septadas (com 1-2 septos) e gelatinosas, presentes. Espessamentos espiralados e traqueídeos, ausentes.

Outros caracteres: variantes cambiais, tubos laticíferos e taniníferos, canais intercelulares, células oleíferas, células mucilaginosas, estratificação e inclusões minerais, ausentes. Máculas medulares, presentes.

\section{2 - Aloysia gratissima (Gillies \& Hook. ex Hook.) Tronc.}

Anéis de crescimento: distintos, evidenciados por faixa de 2-4 fibras radialmente achatadas, por parênquima marginal e o aspecto anelar, resultante da concentração de poros maiores no lenho inicial (Figura 2A,B).

Vasos: numerosos $(94 \pm 19$ (75 - 125) poros $/ \mathrm{mm}^{2}$ ), em porosidade semi-difusa, tendente a anelar, ocupando $24 \pm 3,4 \%$ do volume da 


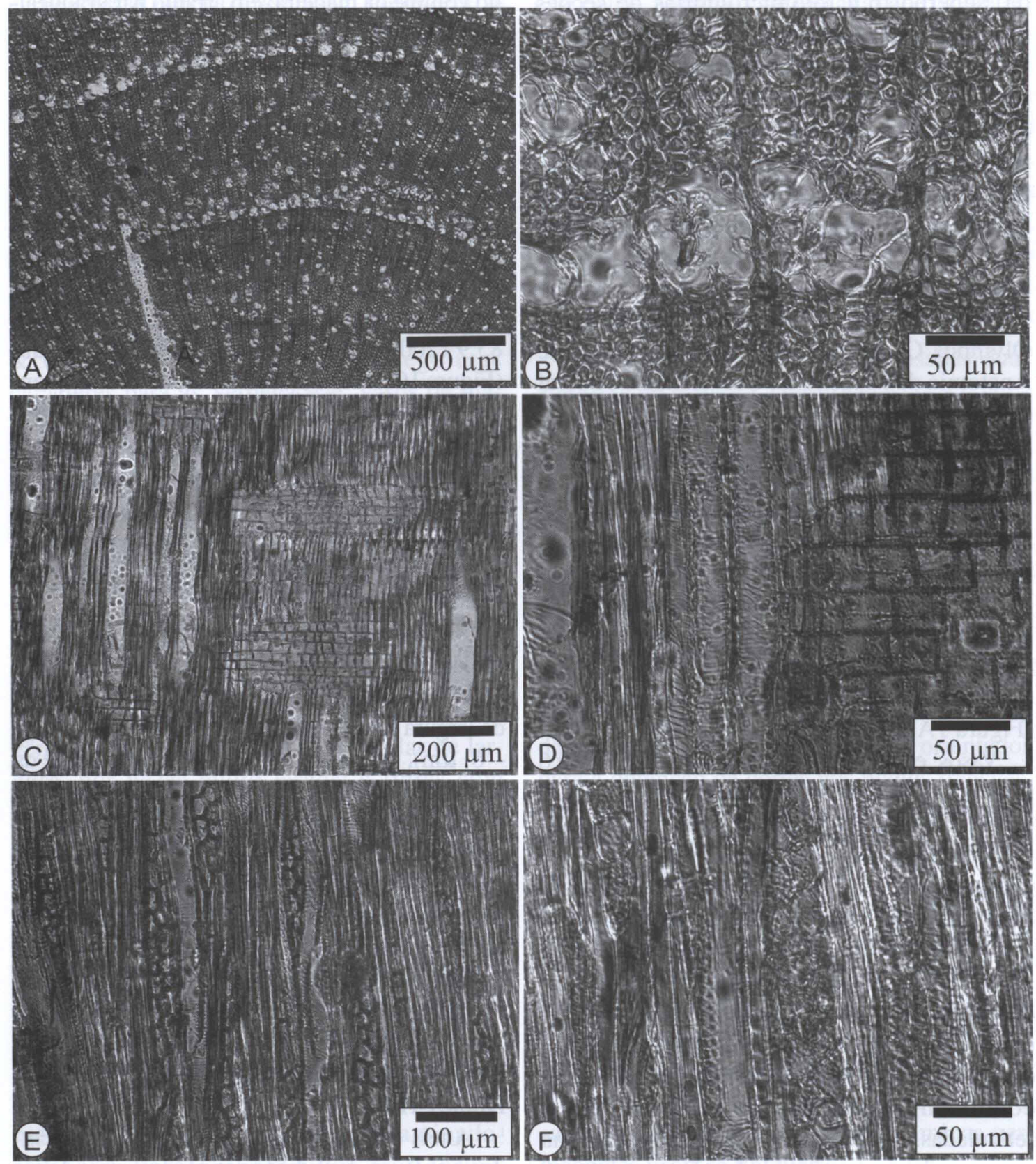

FIGURA 1 - Aspectos anatômicos do lenho de Aloysia chamaedryfolia Cham. A - Limites de anel de crescimento, porosidade semi-difusa tendente a anelar, e poros em múltiplos radiais, racemiformes e solitários (seção transversal). B - Mesma seção, em maior aumento, destacando poros de maior diâmetro no lenho inicial. C - Raios heterogêneos, em seção longitudinal radial, com células eretas, quadradas e procumbentes. D - Elementos vasculares com espessamentos espiralados e parte de raio com células quadradas e procumbentes (seção longitudinal radial). E - Aspecto da seção longitudinal tangencial, destacando elementos vasculares, raios uni a trisseriados e fibras. F - Raios bi e trisseriados (seção longitudinal tangencial). 
madeira; solitários, em múltiplos radiais de 24 , menos frequente racemiformes; de seção circular ou oval, por vezes angulares $(46,5 \pm 14,4$ $(25-80) \mu \mathrm{m})$, e de paredes finas a espessas $(3,6 \pm 0,7(2,5-5) \mu \mathrm{m})$ (Figura 2A,B). Elementos vasculares curtos $(273 \pm 43,4(190-$ 370) $\mu \mathrm{m}$ ), com apêndices em uma ou em ambas as extremidades. Placas de perfuração simples (Figura 2C,D), menos frequentemente escalariformes, tendente a reticulada ou irregularmente reticulada. Pontoações intervasculares circulares $(8,3 \pm 0,5(7,2-10,3) \mu \mathrm{m})$, alternas, com abertura em fenda elíptica, inclusa, ornamentada (Figura 2F). Pontoações raiovasculares aparentemente simples, pequenas $(5,8 \pm 0,5(5,1-6,2) \mu \mathrm{m})$. Espessamentos espiralados e conteúdos, presentes (Figura 2C,D).

Parênquima axial: representando 4,5 $\pm 1,6 \%$ do volume da madeira, em arranjo paratraquealescasso (Figura 2A,B). Séries parenquimáticas de $262 \pm 37,9(195$ - 332) $\mu \mathrm{m}$ de altura, compostas de $2-4$ (6) células.

Raios: numerosos $(11 \pm 1,5(9-13)$ raios/ $\mathrm{mm}$ ), heterogêneos, com 1-10 células de largura, ocupando $22,5 \pm 3,2 \%$ do volume da madeira (Figura 2E,F). Os multisseriados, com até seis fileiras de células procumbentes no corpo central e 1-4 células quadradas e/ou eretas nas margens; de $429 \pm 82,9(280-650) \mu \mathrm{m}$ e $14-30$ células de altura (Figura 2C). Os unisseriados, escassos, reúnem células eretas e/ou quadradas; de $178 \pm 41,7(110-300) \mu \mathrm{m}$ e $3-10$ células de altura. Células radiais de paredes disjuntas, cristais e conteúdos, ausentes. Raios axialmente fusionados e agregados, escassos; células envolventes e células perfuradas de raio, presentes.

Fibras: com pontoações simples, nas faces radiais e tangenciais da parede; curtas $(635 \pm$ $67,2(500-750) \mu \mathrm{m})$, com $16,5 \pm 2(15-20) \mu \mathrm{m}$ de largura e paredes finas a espessas $(6 \pm 1,3$ (5$8,7) \mu \mathrm{m}$ ), ocupando $49 \pm 4,6 \%$ do volume da madeira (Figura 2A,B). Fibras septadas (1-3 septos) e gelatinosas, presentes. Espessamentos espiralados e traqueídeos, ausentes.
Outros caracteres: variantes cambiais, tubos laticíferos e taniníferos, canais intercelulares, células oleíferas, células mucilaginosas, estratificação e inclusões minerais, ausentes. Máculas medulares, presentes.

\section{ANÁLISE DA ESTRUTURA ANATÔMICA}

A estrutura microscópica dos lenhos de Aloysia chamaedrifolia e Aloysia gratissima corresponde, em linhas gerais, ao referido por Metcalfe \& Chalk (1972) para as Verbenaceae: vasos de diâmetro pequeno, em múltiplos radiais, solitários e racemiformes; elementos vasculares de comprimento médio, com espessamentos espiralados e apêndices; placas de perfuração simples; pontoações intervasculares de diâmetro médio, alternas e ornamentadas; pontoações raio-vasculares aparentemente simples; parênquima paratraqueal-escasso; raios heterogêneos; e fibras libriformes septadas.

Pontoações ornamentadas e fibras libriformes são reportadas, por Carlquist (2001), para o conjunto da família; porosidadesemidifusa ou em anéis, bem como fibras de paredes finas a espessas, por sua vez, são referidas por Metcalfe \& Chalk (1972) para o gênero Lippia. Com relação ao carbonato de cálcio, citado por Record \& Hess (1949) e Metcalfe \& Chalk (1972) para o gênero Lippia, o caráter não foi observado no presente estudo.

Quanto às variadas placas de perfuração descritas na literatura, no material em estudo foram observados apenas os tipos os tipos múltiplo-escalariforme e escalariforme tendente a reticulado, em Aloysia chamaedrifolia; e múltiplo-escalariforme, múltiplo-escalariforme tendente a reticulado e irregularmente reticulado, em Aloysia gratissima. Embora registrado por Ruddall (1982) para Canthium barbatum (Rubiaceae), o termo múltiplo-radiado consta, apenas, para o gênero Citharexylum, de acordo com Gomes et al. (1989); este tipo de placa, todavia, não foi observado nas espécies em estudo.

A separação anatômica dos lenhos de Aloysia chamaedrifolia e Aloysia gratissima, pode ser 

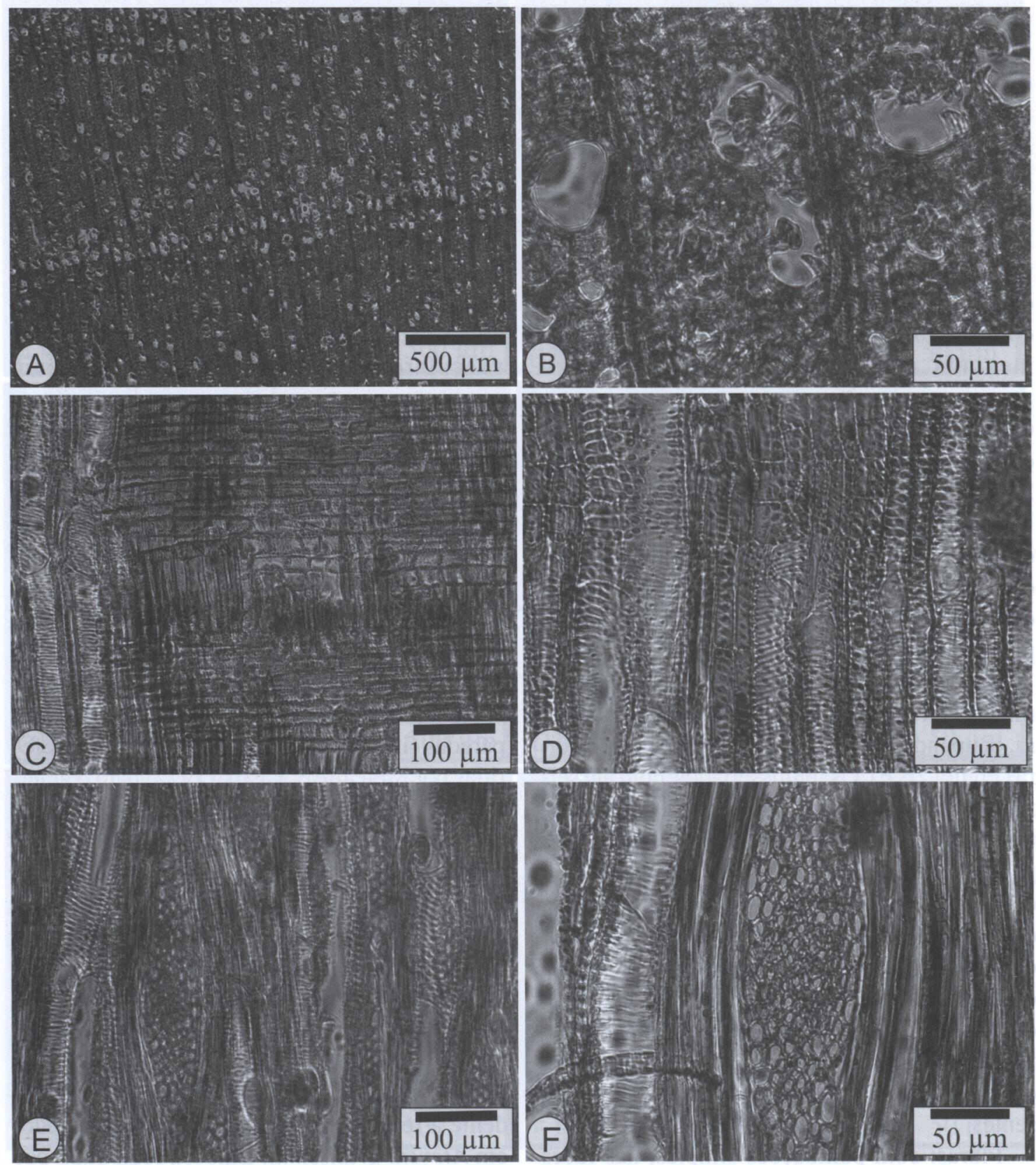

FIGURA 2 -Aspectos anatômicos do lenho de Aloysia gratissima (Gillies \& Hook. ex Hook.) Tronc. A - Seção transversal, destacando porosidade semi-difusa, com poros solitários, em múltiplos radiais, menos comumente racemiformes. B Poros solitários, raios e fibras gelatinosas (seção transversal). C - Raios heterogêneos, com células eretas, quadradas e procumbentes, e elementos de vasculares com espessamentos espiralados (seção longitudinal radial). D - Mesma seção, destacando placa de perfuração simples e elementos vasculares com espessamentos espiralados. E-Elementos vasculares com espessamentos espiralados, raios largos e fibras, em seção longitudinal tangencial. F - Vasos com espessamentos espiralados, raio com células envolventes e fibras (seção longitudinal tangencial). 
realizada pela largura de raios em número de células, visto terem os mesmos de 1-3 células na primeira dessas espécies e até 10 células na última.

\section{REFERÊNCIAS BIBLIOGRÁFICAS}

BRUSSA SANTANDER. C. A.; GRELA GONZÁLEZ. I. C. Flora arbórea del Uruguay. Con énfasis en las especies de Rivera y Tacuarembó. Montevideo: COFUSA, 2007. 542 p.

BURGER, L.M.; RICHTER, H.G. Anatomia da Madeira. São Paulo: Ed. Nobel, 1991. 154 p.

CARLQUIST S. Comparative wood anatomy: systematic, ecological and evolutionary aspects of Dicotyledon woods. Syracuse, USA: Springer, $2001.448 \mathrm{p}$.

DUJARDIN, E.P. Eine neue Holz-Zellulosenfaerbung. Mikrokosmos, n. 53, p. 94, 1964.

FREUND, H. Handbuch der Mikroskopie in der Technik. Frankfurt: Umsham Verlag, 1970. 375 p.

GOMES, A. V.; TEIXEIRA, L. L.; SCHAITZA, E. G.; HOFMEISTER, R. M. Perforation plates in vessels of Citharexylum myrianthum Cham. (Verbenaceae). IAWA Bulletin, v.10, n.1, p. 2734, 1989.

GOMES, V. G.; MARCHIORI, J. N. C.; TEIXEIRA, L, L; SCHAITZA, E. G.; STOFELLA, D. R. E. Anatomia da madeira de Cytharexylum solanaceum Cham. (Verbenaceae). Balduinia, n. 12, p. 13-25, 2008.

GOTTWALD, H.; PARAMESWARAM, N. Vielfache Gefassdurchbrechungen in der Familie Dipterocarpaceae. Zaitschr. F. Bot., n. 52, p. 321334, 1964.
HERNANDEZ T.; CANALES M.; AVILA J. G. Ethnobotany and antibacterial activity of some plants used in traditional medicine of Zapotitlán de las Salinas, Puebla (México). J Ethnopharmacol, n. 88, p. 181-188, 2003.

MARCHIORI, J.N.C. Comprovação da viabilidade da utilização da secção longitudinal tangencial para a determinação histométrica dos elementos axiais do xilema secundário. In: Anais do IV Congresso Florestal Estadual, Nova Prata, RS, p. 180-184, 1980.

MEYLAN, B. A.; BUTTERFIELD, B. G. Occurrence of simple, multiple and combination perforation plates in the vessels of New Zealand woods. New Zeal. J. Bot., n. 13, p. 1-18, 1975.

METCALFE, C.R.; CHALK, L. Anatomy of the Dicotyledons. Oxford: Clarendon Press, 1972. p. 1030-1041.

RECORD, S.J.; HESS, R.W. Timbers of the New World. New Haven: Yale University Press, 1949. p. 436-443.

RUDDALLP. J. An unusual type of perforation plate in Canthium barbatum (Rubiaceae). IAWA Bull., n. 3, p 127-129, 1982.

SOUZA, V.C.; LORENZI, H. Botânica Sistemática: guia ilustrado para identificação das famílias de Angiospermas da flora brasileira, baseado em APG III. Nova Odessa: Instituto Plantarum, 2012. p. 674-678.

WHEELER, E.A.; BAAS, P.; GASSON, P.E. IAWA list of microscopic features for hardwood identification. IAWA Bulletin, v.10, n. 3, p. 218359, 1989. 